\title{
As redes de solidariedade da cor: o caso dos compadres Manoel e
}

\section{Lauriano}

Ivan de Andrade Vellasco*

\section{Resumo:}

O artigo baseia-se na analise de um processo criminal de 1831, no qual os réus, pardos, são acusados de assassinar um homem branco. No teor dos depoimentos revela-se a formação de uma aliança solidária dos pardos, em função das categorias que definem as posições e juízos a respeito do crime. Testemunhas pardas e crioulas, livres e forras, produzem um consenso construindo uma versão contra a vítima, o homem branco. Uma visão sobre o certo e o errado solidariza a todos e, dentro dela, uma percepção específica da justiça une pardos, crioulos e cabras. Propõe-se que a solidariedade com base na identidade entre "pardos" possa ter tido uma intencionalidade e motivações associadas aos debates políticos da época, travados entre liberais moderados e conservadores, a respeito da conceituação e inclusão dos 'pardos' no projeto de nação. Representa uma tentativa de se captar, nos indícios disponíveis, a formação de processos identitários com base na cor e na condição, categorias ordenadoras fundamentais da sociedade escravista.

Palavras-chave: pardos, redes de solidariedade, identidade.

"Marie-Sophie, não acredite nisso não, tinha o negócio da cor, mas também tinha o negócio da maneira e dos ares afetados. Com a maneira e os ares afetados você era visto como mulato, de tal forma que os mulatos eram às vezes bem pretos. Mas um mulato de pele (sem falar do branco) permanecia o que era sem a maneira ou os ares afetados. É complicado, mas aqui está o verdadeiro fio da meada: os melhores ares afetados eram ter a pele sem cor de escravidão. E que cor de pele tinha a escravidão?

Que cor?"

Patrick Chamoiseau, TEXACO.

\section{Introdução}

Processos criminais têm sido crescentemente utilizados por historiadores como fonte para os mais diversos temas de pesquisa. Documentação rica em vários aspectos, presta-se como uma janela através da qual é possível enxergar indícios e sinais, como define Ginsburg, que nos conduzem às mais diferentes imagens da vida social e das relações que predominavam na sociedade em determinada época ${ }^{1}$. Ao recontarem e 
reconstruírem eventos circunscritos, muitas das vezes banais em suas dimensões e alcance, como brigas de vizinhos, agressões verbais, ou ainda acontecimentos cuja dramaticidade do desenlace já se perdeu no tempo, como assassinatos e crimes violentos, esses documentos espelham e retratam as formas do viver, os modos de ser e agir numa dada formação social. Se não são confiáveis quando se trata de aquilatar o peso de certas práticas no cotidiano da época, uma vez que sua produção deriva exatamente de práticas específicas criminalizáveis que venham a ser objeto da ação judicial, são, no entanto, e por isso mesmo, uma fonte de entrada direta nos momentos de exceção, no conflito, na suspensão da norma cotidiana.

Processos judiciais constituem fragmentos que, ao registrarem relações conflituosas e as formas de resposta aos conflitos, nos permitem enxergar, em negativo, as regras que regiam as condutas cotidianas $\mathrm{e}$ as expectativas recíprocas de comportamentos que deveriam prevalecer na relação entre indivíduos distintos e grupos socialmente delimitados, regras que balizavam os limites entre a aquiescência e a desobediência, entre o acatamento e a reinterpretação da regra, quando ela se tornava fonte de conflito e negociação.

Assim, podemos enxergar nas reações violentas que se tornam depois alvo da ação dos aparatos coativos, a expressão de um conflito em torno da norma, ou, mais comumente, um conflito gerado entre normas dissonantes, entre o que prescrevem os códigos legais e o que determinam as obrigações derivadas, por exemplo, dos códigos morais implícitos. Isso significa não pensar os conflitos como excepcionalidades que apenas confirmariam, como reações limites, a existência das regras, ou, em outros termos, não supor que o não acatamento de regras e das situações de dominação que elas buscam reproduzir signifique sua negação reativa, a ruptura da ordem.

Regras e normas sociais não formam um todo coerente e funcional para a dominação, como querem algumas análises. São intrinsecamente contraditórias por expressarem situações contraditórias de domínio, são instáveis porque representam "acordos" tácitos, temporários e precários em torno das condições postas pelas relações de dominação que não se reproduzem sem conflito; e é esse caráter intrinsecamente hábil que as torna manipuláveis na prática e nas formas de pensá-las. Como afirma Van Velsen, "normas e regras gerais de conduta são traduzidas em prática; estas são, em última análise, manipuladas por indivíduos em situações específicas para servirem a fins específicos" ${ }^{2}$. Segundo o autor, 
as normas da sociedade não constituem um todo coerente e consistente. São, ao contrário, freqüentemente vagas e discrepantes. É exatamente este fato que permite a sua manipulação por parte dos membros da sociedade no sentido de favorecer seus próprios objetivos sem necessariamente prejudicar sua estrutura aparentemente duradoura de relações sociais ${ }^{3}$.

Este artigo apresenta algumas reflexões baseadas na análise de um processo criminal cujo interesse reside sobretudo no modo como, no seu desenrolar, os depoimentos das testemunhas constroem uma versão que acaba por definir os rumos do processo e consubstanciar o argumento central da defesa e do veredicto do julgamento, e aí, em particular, o modo como são mobilizadas determinadas categorias que se repetem nos testemunhos ${ }^{4}$. Trata-se do homicídio de um homem branco, Antônio Dias de Carvalho, ocorrido em 1830 e pelo qual são acusados Manoel Machado e Lauriano José de Souza, ambos pardos.

Embora já tivesse lido este processo há algum tempo, não haviam inicialmente me chamado a atenção determinadas relações prováveis com o contexto mais amplo no qual se desenrola a narrativa construída no documento. A partir de certas leituras posteriores, resolvi relê-lo, agora considerando novas possibilidades interpretativas. Antes, porém, de apresentar mais detalhadamente o processo, faz-se necessário tecer algumas breves considerações a respeito do lugar e papel das testemunhas no cerimonial da justiça.

\section{O lugar das testemunhas e o poder da vox populi}

Chamava-me a atenção no processo, além da estratégia usada pelos réus, como veremos, a atuação decisiva das testemunhas, em sua maioria, pardos, cabras e crioulos, moradoras do pequeno arraial no qual o crime acontecera e onde declaravam viver de suas "agências" e ofícios mecânicos.

À medida que nos familiarizamos com processos criminais da primeira metade do oitocentos, vamos nos dando conta de que forros, livres pobres, homens de condição modesta, roceiros, pequenos lavradores, artesãos, vendeiros e lavadeiras formavam um universo de personagens que, na qualidade de testemunhas, se faziam presentes no cerimonial da justiça, atuando nos processos de forma decisiva, uma vez que, mais do que as provas materiais - em geral inexistentes - seus depoimentos é que conformavam as evidências da culpa ou da inocência dos acusados. 
Vale lembrar que, segundo o Código do Processo Criminal, no artigo 134, bastavam para a formação do auto de corpo de delito, na inexistência de "vestígios que podem ser ocularmente examinados (...) duas testemunhas, que deponham da existência do fato e suas circunstâncias". Para proceder à formação de culpa era suficiente que o juiz procedesse "à inquirição de duas até cinco testemunhas que tiverem notícia da existência do delito e de quem seja o criminoso". A lei da reforma de 1841 ampliaria esse número, nos casos de denúncia, para "cinco até oito testemunhas". Entretanto, o que se constata na leitura dos documentos é que a quantidade de testemunhas era freqüentemente superior, alcançando não raro o envolvimento de 20,30 ou mais pessoas. No decorrer dos processos, juízes, advogados e solicitadores faziam comparecer na justiça todos os que tivessem qualquer declaração a prestar não necessariamente a respeito do crime em pauta, mas também a respeito dos envolvidos, réus e ofendidos, suas condutas rotineiras e seus antecedentes.

A participação ampliada de testemunhas no desenrolar dos processos, além de indicar um elevado grau de envolvimento e comprometimento com o processamento judiciário e seus resultados, possibilitava à população, e notadamente aos homens e mulheres pobres, espaços de afirmação de representações próprias sobre a ordem e a justiça.

As considerações feitas por José Murilo de Carvalho em relação à participação da população no exercício do poder judiciário, na qualidade de jurado, são inteiramente pertinentes às questões desenvolvidas aqui. Em artigo no qual propõe temas para o estudo do desenvolvimento da cidadania no Brasil, entre eles a participação no sistema de justiça, o autor afirma que "não há como comparar o ato rápido de votar com a demorada exposição às leis e aos procedimentos judiciais exigida pelo exercício da função de jurado", no qual "o contato com o Estado era mais profundo e pode-se razoavelmente supor que a socialização política dele resultante também fosse mais eficaz" ${ }^{6}$. O mesmo raciocínio pode ser feito em relação às testemunhas. A participação das testemunhas nas cortes possibilitava a elas uma experiência da lógica jurídica, mas, sobretudo, lhes permitia afirmar direitos, apresentar suas noções de justiça e seus "julgamentos" a respeito do caso em pauta e, como resultado, intervir decididamente nos rumos da ação.

A leitura de processos judiciais nos vai deixando a nítida percepção de que esses momentos, nos quais eram chamados a testemunhar pardos livres, forros, homens de cor, mas também brancos pobres - enfim, aqueles que formavam os grupos sociais que 
existiam na fronteira entre a liberdade e a escravidão e formavam a base da pirâmide dos livres -, eram percebidos por eles como oportunidade de afirmar suas visões de mundo, fazer valer seus valores e exercer o direito de formar juízo da realidade e fazê-lo intervir na interpretação dos fatos.

Isso se evidencia nos processos e no modo como são montados, no que diz respeito ao papel atribuído às testemunhas chamadas pelas autoridades judiciais a revelar uma espécie de perfil sociocomportamental do réu. Assim, os depoimentos de vizinhos, parentes e agregados - os iguais das partes envolvidas - constroem uma espécie de perfil pregresso, um quadro de referências sobre quem era o réu, como costumava agir, enfim, revelando uma voz corrente a seu respeito. Perguntava-se sobre a conduta costumeira do réu, se era "turbulento e rixozo" e dado à violência, por exemplo; as testemunhas, vivendo nas mesmas condições do réu e da vítima, emitiam suas opiniões - e muitas das vezes não passavam de opiniões - sobre quem era e o que teria feito o réu. Com expressões como "sabe por ver" e "sabe por ouvir dizer e ser público e notório", vai-se desenhando uma avaliação pública sobre o réu e o que se diz sobre seu perfil moral e propensões, bem como seu envolvimento com o fato em julgamento. Essa vox populi vai definindo as características, o desenrolar e, finalmente, os resultados do processo - já que residiam aí as fontes básicas de elucidação do delito ocorrido, acabando por constituir o campo de argumentos que definirá a sorte ou o azar do réu. O quadro seguinte, arrolando a testemunhas do processo de Manoel e Lauriano, permite visualizar em parte o que está sendo dito (Quadro 1): 
1-QUADRO DAS TESTEMUNHAS - PROCESSO MANOEL E LAURIANO

\begin{tabular}{|c|c|c|c|}
\hline TESTEMUNHAS & COR/CONDIÇÃO & OCUPAÇÃO & VER OU OUVIR \\
\hline JOSE ANTONIO DE ANDRADE & BRANCO & VIVE DE SUA AGÊNCIA & SABE POR SER PÚBLICO \\
\hline JOSE PEDRO & PARDO & VIVE DE SUA AGÊNCIA & SABE POR VER \\
\hline JOAO DA COSTA & BRANCO & VIVE DE SUA AGÊNCIA & SABE POR VER \\
\hline FRANCISCO MARINQUES & BRANCO & VIVE DE LAVOURA & SABE POR VER \\
\hline JOAQUIM DA SILVA CABO & PARDO & $\begin{array}{l}\text { VIVE DE SEU NEGOCIO DE } \\
\text { VENDA DE TERRA }\end{array}$ & OUVIDO DIZER \\
\hline ANTONIO JOAQUIM DA SILVA & PARDO & & SABE POR VER \\
\hline RITA MARIA DE JESUS & BRANCO & VIVE DE SUA AGÊNCIA & SABE POR SER PÚBLICO \\
\hline MARIA TEODORA & & VIVE DE SUA AGÊNCIA & SABE POR VER \\
\hline ANA JOAQUINA & PARDO & VIVE DE SUA AGÊNCIA & SABE POR VER \\
\hline MARIA RISOLINA DE JESUS & BRANCO & VIVE DE SUA AGÊNCIA & SABE POR VER \\
\hline PEDRO DA SILVA CORREIA & CRIOULO FORRO & VIVE DE SEU NEGÓCIO & SABE POR SER PÚBLICO \\
\hline CLEMENTINA DA SILA & PARDO & VIVE DE SUA AGÊNCIA & SABE POR SER PÚBLICO \\
\hline MARIA ROSA DA SILVEIRA & PARDO & VIVE DA SUA AGÊNCIA & SABE POR SER PÚBLICO \\
\hline MARIA URSULA DA SILVA & PARDO & VIVE DA SUA AGÊNCIA & \\
\hline FRANCISCO DE PAULA & BRANCO & VIVE DE SUA AGÊNCIA & SABE POR SER PÚBLICO \\
\hline ANA FERNANDES & CRIOULO FORRO & VIVE DE SUA AGÊNCIA & \\
\hline JOSE & PARDO & VIVE DE SUA AGÊNCIA & SABE POR SER PÚBLICO \\
\hline FRANCISCA ANTONIA DE JESUS & CRIOULO & VIVE DE SUA AGÊNCIA & \\
\hline ANA FERNANDES & CRIOULO & VIVE DE SUA AGÊNCIA & OUVIDO DIZER \\
\hline JERONIMO RODRIGUES DA SILVA & BRANCO & VIVE DE NEGÓCIO & OUVIDO DIZER \\
\hline $\begin{array}{l}\text { ANTONIO VALERIANO TEIXEIRA } \\
\text { DE CARVALHO }\end{array}$ & BRANCO & OFICIO DE LENHEIRO & \\
\hline LUIS BRITO & CABRA & OFICIO DE FERREIRO & VIU A BRIGA \\
\hline BENTO MANOEL ANTONIO & PARDO & VIVE DE SUA AGÊNCIA & OUVIDO DIZER \\
\hline DOMINGOS ALVES DE RAMOS & BRANCO & VIVE DE NEGÓCIO & SABE POR SER PÚBLICO \\
\hline VENANCIO DA SILVA & PARDO & VIVE DE SUA AGÊNCIA & SABE POR SER PÚBLICO \\
\hline $\begin{array}{lll}\text { ANTONIO } & \text { FRANCISCO } & \text { DE } \\
\text { ALMEIDA } & & \\
\end{array}$ & BRANCO & VIVE DE SUA AGÊNCIA & OUVIDO DIZER \\
\hline PATRICIO GONÇALVES PINHEIRO & CABRA & VIVE DE SUA AGÊNCIA & \\
\hline TOMÁS ALVES DE AQUINO & BRANCO & & SABE POR SER PÚBLICO \\
\hline CUSTÓDIO PEREIRA MUNIZ & BRANCO & & SABE POR SER PÚBLICO \\
\hline MANOEL DE OLIVEIRA & BRANCO & GUARDA DO PORTO REAL & SABE POR VER \\
\hline CONSTANTINO JOSÉ DE CASTRO & PARDO & $\begin{array}{|llll|}\text { VIVE DE } & \text { SEU OFÍCIO } & \text { DE } \\
\text { JUSTIÇA }\end{array}$ & OUVIDO DIZER \\
\hline
\end{tabular}

O quadro apresenta o total das trinta e uma testemunhas, somadas às que depõem na primeira fase do processo as que aparecem em documento posterior, e certamente depuseram no julgamento, diante do júri. Os dados sobre cor e ocupação das testemunhas indicam uma ampla maioria de pessoas "de cor" - pardos, crioulos e cabras que, por sua ocupação, situam-se nas camadas mais pobres da sociedade da época. Destas, a maioria é formada por moradores do arraial que "souberam por ver" parte da cena ou a movimentação que ela causou, ou sabiam "por ser público e notório" ou "por ouvir dizer". Chamados a depor, muitos deles não apenas respondiam sobre o que teriam visto ou ouvido, mas apresentavam uma versão dos acontecimentos que 
estava longe de se basear em informações seguras. Ao final do julgamento de Lauriano, por exemplo, ficamos sabendo que algumas das testemunhas que disseram ter presenciado sua participação na morte de Antonio Dias, o teriam declarado para prejudicá-lo e, por serem seus desafetos, "intentaram criminar ao réu" (sic). Se era ou não verdade não vem ao caso aqui. $O$ que importa é que as testemunhas tinham consciência do poder e alcance de suas declarações perante a justiça.

\section{Os crimes dos compadres Machado e Lauriano}

Vejamos a história de Manuel Machado e Lauriano José de Souza. O crime ocorreu no ano de 1830 e o processo se estenderá por quase todo o ano seguinte. Iniciava-se então uma década que marcou a presença da elite política regional nos rumos do Estado emergente e o crescente envolvimento dos políticos da região no desenvolvimento e no desenlace da crise do primeiro reinado ${ }^{7}$. Por esse momento, a província de Minas Gerais atravessava, como o restante da jovem nação, o ápice da luta política entre Liberais e Conservadores, que desembocará na abdicação de D. Pedro e na Regência. Retornarei a este contexto mais à frente, tomando-o como uma provável variável nas hipóteses explicativas tentadas.

No dia cinco de setembro daquele ano, às seis horas da tarde, durante a novena de Nossa Senhora, os réus teriam assassinado Antônio Dias de Carvalho, homem branco, com ferimentos provocados por instrumentos cortantes dos quais "houve grande infusão de sangue", o que provocou a morte da vítima poucas horas depois. O crime ocorreu no Arraial do Córrego, curato da vila de São José, um pequeno arraial no caminho que levava ao Porto Real da Passagem e à vila de São João, com 76 fogos e 266 almas, um pouco mais um pouco menos ${ }^{8}$.

Os réus eram ambos pardos e o eram também a maioria das testemunhas, como vimos. Por essa época, os pardos já formavam uma grande massa da população regional e se faziam presentes nas mais diversas atividades econômicas, com forte presença nos variados ofícios manuais.

Vários estudos já apontaram para o fato de que a maior intensidade e amplitude das práticas de alforria caracterizaram o escravismo brasileiro, quando comparado com outras experiências. Em Minas Gerais, como afirmam Douglas Libby e Clotilde Paiva, as alforrias foram responsáveis pelo enorme crescimento da população negra livre e seus descendentes durante o período colonial e o Império ${ }^{9}$. Trabalhando 
especificamente com documentação produzida na última década do Setecentos na vila de São José del Rei, vila a cujo termo pertencia o arraial do córrego no qual nossos personagens teriam cometido o crime algumas décadas após, Libby e Paiva apresentam uma distribuição populacional da Paróquia, na qual brancos totalizavam 2.377, africanos 3.408 e mulatos, cabras e mestiços somavam 5.070, num total de 10855 almas. Quando computada apenas a população livre, os dados indicavam um total de 2.377 brancos, 1.390 pardos, 252 crioulos, 62 cabras e 69 mestiços ${ }^{10}$.

Duas décadas após, os dados coligidos por Cunha Matos para o ano de 1821 confirmavam a grande presença dos pardos na população livre ${ }^{11}$. No termo da vila de São José, a população livre era composta de 8.233 brancos, 5.234 pardos e 2.132 $\operatorname{pretos}^{12}$. As tensões advindas desse quadro populacional se evidenciavam nos processos que narravam os conflitos ocorridos entre pardos, crioulos, cabras e brancos pobres. Como afirma Ana Rosa C. Silva,

No quadro da sociedade mineira da primeira metade do século XIX, estas tensões repousavam, ainda, no já mencionado fato de haver um enorme contingente de pardos - livres e forros - os quais, já parcialmente contemplados pelas conquistas materiais em curso, passavam a demandar, também, um lugar na esfera da representação política. A este problema as elites dominantes não puderam ser alheias, devendo, por um lado, forjar o seu equacionamento, do qual dependia a própria construção do consenso social em torno dos projetos alternativos por ela encampados; por outro, acomodar essas demandas preservando um senso de identidade fincado na distinção racial e social ${ }^{13}$.

Mas voltemos ao processo para vermos como a longa citação se presta a indicar aspectos que serão centrais na interpretação que tento do documento e na compreensão de suas circunstanciais. Vejamos, então, o que se passou. Segundo uma das testemunhas, o caso se dera da seguinte maneira:

estando ele testemunha em sua casa aprontando-se para sair com sua família a ir assistir as novenas de Nossa senhora da Natividade (...) ouviu ele testemunha uma gritaria assim como conheceu a voz de Manuel Machado [e gritos de] não matem o meu marido, e daí a mulher da testemunha abriu a porta e logo entrou Manuel Machado com uma espada na mão e a outra mão muito ensangüentada dizendo ele que lhe tinham cortado os dedos e daí saiu ele testemunha, fechou a sua porta e logo chegou a mulher de Lauriano de tal e perguntando ele testemunha que desordem foi esta, [ela diz] eu ia cá atrás e vi dois vultos chegar[sic], um era o falecido [Antonio Dias] e outro o não conhecia e dizendo o falecido a ele Machado "aqui é que se pagam elas" e o Machado e aquele Lauriano responderam "também estou pronto" e meteram logo mãos aos ferros 
que traziam e aí houve a desordem e morte, e que sabe por ouvir dizer que o vulto que vinha com o falecido fora seu cunhado Patrício Gonçalves ${ }^{14}$.

A tocaia armada por Antônio Dias, a vítima no processo, e seu cunhado Patrício Gonçalves, contra Manuel Machado, tinha como motivo, segundo as testemunhas, uma rixa anterior, que "principiara em um Domingo transato (...) por causa de jogo onde houve descomposturas e brigas do falecido com o dito Machado". No dia do crime, Antônio Dias e Patrício aguardaram Manuel na saída da novena. Este vinha acompanhado de sua mulher e de seu amigo Lauriano, também com a mulher e os filhos. A briga envolvendo os quatro resultou no ferimento de Manuel e na morte de Antônio Dias. Segundo o auto de corpo de delito, a morte fora conseqüência de duas incisões profundas, "a primeira com instrumento cortante, que vem a ser foice ou machado, e a segunda com instrumento de espada e deles houve grande infusão de sangue em que veio a morrer em poucas horas"

À medida que os depoimentos vão se somando, começa a ser desvendada uma história que, reconstruindo os antecedentes da briga, vai apontando os responsáveis pelo trágico acontecimento e o modo como as testemunhas os julgam, com sutis diferenças. Embora os depoimentos variem no relato do crime, em apontar ou não o envolvimento direto dos réus, enfim, na "fábula" que $\operatorname{contam}^{16}$, a maior parte deles vai apontar a responsabilidade da vítima no desenlace dos acontecimentos. À exceção de duas testemunhas brancas, o restante é quase unânime em afirmar, por "saber por ouvir dizer" ou por "ser público e notório", que a vítima, "que era homem mau por natureza", armara a tocaia "a esperar de propósito" com o objetivo de vingar-se de rixas anteriores havidas com Manuel. Todos confirmam, com diferentes palavras e ênfases, a mesma história. E aí começa a avultar-se o papel de Patrício Gonçalves, parceiro e cunhado da vítima. Teria sido ele o principal responsável que "fomentara esse assassínio", tendo “instigado" e "incendiado" Antônio Dias a vingar-se "dos desaforos" que Manuel lhe fizera.

Das 31 testemunhas arroladas no processo, 13 são denominadas "brancas", duas “cabras", quatro designadas "crioulas" e 11 "pardas". Cabras, crioulos e pardos, homens e mulheres "de cor" formam, portanto, uma ampla maioria. Entre as 13 testemunhas brancas, seis se referem a Patrício como o instigador da tocaia e dos planos de vingança; entre os 17 "de cor", 10 denunciam o papel de Iago desempenhado por Patrício. A diferença é relevante pelo fato de dois dos pardos e um crioulo acrescentarem o 
argumento que Patrício teria usado para convencer seu cunhado: a cor de Manuel. Um deles afirma que "ele fomentou dizendo que em um negro que passava a mão em um branco se dava pancadas", acrescentando que "Patrício de tal no mesmo dia [do crime] disse a ele testemunha "eu dei uma porretada no negro que é o dito Machado"”; outro afirmou que ele incitara o "falecido a ir fazer esse distúrbio" dizendo que "um homem que nunca foi desfeitado não deveria ficar assim e muito mais de um negro que era o Machado"; por último, o crioulo forro Pedro da Silva depõe afirmando que

Patrício dissera ao falecido que era desaforo um negro dar em um branco e que se havia de desforrar, ao que respondia o falecido "isso já passou", [e] ele perto mais dizia "tu então um homem de tanta fama há de ficar assim com um negro, tu não tens vergonha", e assim por este modo reduzira ao dito cunhado para a sua morte. (grifos meus)

Todos vão construindo uma versão que aponta para a culpa do cunhado Patrício. Mesmo o testemunho de João Costa, que seria depois acusado por outras testemunhas de tentar incriminar Lauriano, envolvendo-o na cena do crime por ser seu desafeto, afirma que Patrício teria dito a Antônio Dias "vós é [sic] um homem que tem fama de valentão, pega a arma que tem e vás disfarçar com aquele negro Manuel Machado". A diferença é que aqui a cor não é o elemento central nem é acrescida da dramatização operada pela recriação dos enfáticos diálogos acima. Manuel, que no processo é descrito como pardo, é tratado como "negro" por Patrício, que instigava a vingança, e serão crioulos e pardos as testemunhas que denunciarão as motivações de Patrício e, com isso, definirão sua solidariedade para com Manoel. Solidariedade que se fazia presente nos demais pardos e crioulos que, ainda que não se referindo à cor, acusavam e condenavam Patrício e sua conduta.

É interessante chamar a atenção do leitor para o fato de que nenhuma das testemunhas ouvira o teor das declarações de Patrício a Antônio Dias, os supostos diálogos que teriam ocorrido entre os dois diante da presença da mulher de Antonio Dias, segundo um dos testemunhos, e de uma vizinha, segundo outro. Portanto, a recriação do diálogo, das frases que teriam sido ditas pelo cunhado de Antônio, dos termos por ele usados são ficções que se prestam mais a ilustrar o que as testemunhas quiseram realçar do que reconstituir a "verdade". Daí não ser mera coincidência o fato de terem sido pardos e crioulos os que escolheram enfatizar o viés racial nos argumentos que Patrício teria usado para convencer Antônio Dias a ir à desforra, assim 
como terem sido eles a enfatizar a palavra "negro", nitidamente ofensiva pelo que carregava de significado colado à escravidão, e, por fim, ter sido um crioulo forro o que mais fortemente carregou nas tintas.

De todo modo, os depoimentos acabam por definir um consenso que condena os "causadores da desordem", sobretudo Patrício, por instigar a tocaia e, entre os pardos, crioulos e cabras, por seu racismo. Uma visão sobre o certo e o errado solidariza a todos e, dentro dela, uma percepção mais específica da justiça une os homens de cor.

As disputas entre pardos, brancos, crioulos, escravos ou forros eram recorrentes, pelo que se pode depreender da leitura da documentação da época. Habitantes de um mesmo espaço social, brancos pobres, pardos, e crioulos forros, muitos deles vivendo de "suas agências" e ligados a ofícios mecânicos, parecem ter vivido em uma espécie de área de "fricção interétnica" "17 na qual os conflitos eram constantes e suas motivações freqüentemente se relacionavam à necessidade de manutenção de uma hierarquia social definida pela cor, atributo de uma posição social. Sobretudo é entre pardos e brancos que os conflitos parecem se avolumar no período, e muitos deles posteriormente se materializaram em documentos da justiça. Uma parte significativa deles é constituída por agressões mútuas, que emergiam nas mais variadas situações sociais, envolvendo freqüentes disputas em torno da hierarquia social que deveria regular as relações entre brancos e a "gente de cor".

Como nos acontecimentos aqui narrados, muitos desses conflitos surgiam da reação de "brancos" ao que consideravam afronta de "pardos" e "negros". Desafiados por "homens de cor", agredidos em sua honra e ameaçados em sua posição hierárquica, muitos "brancos" reagiam como Patrício aconselhou a Antônio Dias, não aceitando desfeitas de "negros". Ocorre que, exatamente naquele momento, essas disputas vinham se intensificando e ganhando novos significados, inscritos nas lutas política que, entre outras coisas, redefiniam identidades, inserções e direitos em função das idéias em disputa sobre a nação que se pretendia construir.

No início dos anos trinta ocorre um nítido aumento de processos nos quais pardos figuram como réus. É interessante ainda acrescentar que a análise dos registros criminais demonstra que a quase-totalidade dos crimes praticados por pardos nesse período referem-se a conflitos interpessoais, resultando em agressões físicas, tentativas de homicídios e homicídios. Só podemos especular sobre as razões desse aumento e a relação que teria com a conjuntura de acirramento das tensões entre pardos e brancos. A maior parte desses crimes corresponde a lançamentos nos livros de Rol dos Culpados 
sem que exista o processo correspondente ${ }^{18}$. Assim, são escassas as informações que poderiam nos colocar em terreno mais firme de análise empírica. De qualquer forma, é digno de nota que o aumento de conflitos envolvendo pardos registrado no período seja congruente com o fato de que, efetivamente, e em amplas áreas do território brasileiro, a emergência dos pardos na arena política, afirmando uma identidade social que se projetava com contornos que vinham se delineando no processo de independência, produzia com frequiência situações de conflito, opondo estes a brancos e "portugueses".

As análises de Gladys Sabina Ribeiro - que buscam explicitar e interpretar a participação dos "homens de cor" nas lutas travadas na Corte durante o processo de aprofundamento da Independência no final dos anos 1820 e início dos anos 1830 demonstram como particularmente esse período caracterizou-se por uma crescente manifestação de uma "consciência" das questões relativas à cor e à condição dos pardos, crioulos e "negros", livres e escravos. A autora aponta o "clima de rixas e rivalidades entre os dois grupos específicos: de um lado, os 'negros' - africanos e crioulos 'pardos' e 'cabras'; de outro, os 'portugueses'- 'brancos", ${ }^{\prime \prime}$. Isso ganhava contornos nítidos nos enfrentamentos de rua - como na "Noite das Garrafadas", nos conflitos entre tropas, soldados e marinheiros, nas tentativas do governo regencial de controlar as milícias e suas ações na repressão aos ajuntamentos da "gente de cor" ${ }^{20}$.

Havia um incitamento à ação e ao enfrentamento das questões específicas da "gente de cor", exemplificado, por exemplo, em periódicos como "O Homem de Cor" e "O Brasileiro Pardo". O trabalho de Ivana Stolze Lima analisa os periódicos da época e o lugar da "cor" na trama das identidades, ressaltando três aspectos que interessam aqui de perto: a mudança que estava sendo operada no significado dos termos "homem de cor" e "mulato" naquele momento; a associação destes com os exaltados e a radicalização e o aprofundamento da ação política; a luta pela igualdade de direitos, no caso específico, igualdade de acesso a cargos e patentes ${ }^{21}$.

Na região central da comarca do Rio das Mortes e, sobretudo, na vila de São João del Rei, razões específicas faziam que os conflitos que se generalizavam no território nacional ganhassem contornos locais. A população da Comarca havia aumentado significativamente, passando de 154.869 em 1808 a 213.617 em $1821^{22}$. Além da migração interna, a Comarca, por sua localização e possibilidades de negócios, atraía os emigrantes europeus, sobretudo portugueses, em busca das "melhores oportunidades de fazer fortuna, no meio de um povo dado ao comércio e à agricultura, que nas zonas auríferas, onde não se pode esperar um verdadeiro sucesso senão com 
auxílio de um capital já adquirido"23. Comentando o afluxo de portugueses para a região e sua presença na vila de São João, Saint-Hilaire faz as seguintes observações, que não disfarçam a antipatia que nutria por eles:

Como já disse, a população comercial da vila é renovada incessantemente por jovens vindos das províncias as mais distantes, de Portugal, jovens que não receberam educação nenhuma, mas que são orgulhosos de terem nascido na Europa. Após servirem como caixeiro, esses jovens começam a negociar por conta própria; tornando-se negociantes, conservam toda a grosseria de seus costumes, mostrando mais orgulho que anteriormente, porquanto já possuem alguma coisa. Por sua vez fazem vir da Europa, para aprender o comércio, homens de suas famílias, tão sem educação quanto eles. ${ }^{24}$

Esse contingente de portugueses jovens recém-chegados, muitos deles pobres, que vinham trabalhar e se empregar em ocupações disputadas também pelos "pardos" e gente da terra, rivalizava nos mais diversos espaços sociais com a enorme população de "pardos" livres e libertos que aqui encontraram.

A imprensa local viveu seu período de glória durante o espaço de tempo que decorre do final dos anos 20 a meados dos anos 40, quando, em 1844, deixa de circular o último jornal ainda ativo do período. Nesse tempo, 12 periódicos tiveram existência. Além do "Astro de Minas" (1827-1839), circularam nos anos trinta "O Amigo da Verdade" (1829-1831), “A Constituição em Triunfo" (1830), "O Constitucional Mineiro” (1832-1833), “O Mentor das Brasileiras” (1829-1832), “O Papagaio” (1832), “A Legalidade em Triunfo" (1833), “Oposição Constitucional” (1835), “O Monarquista" $(1838)^{25}$.

Tendo como função precípua publicizar as posições políticas dos grupos que os sustentavam, os jornais reproduziam matérias publicadas nos periódicos da Corte e ecoavam, com cores locais, os debates políticos nacionais ${ }^{26}$. Como afirma Lenharo, a reprodução de artigos e editoriais dos jornais editados na Corte cumpriam o papel de “internalizar entre a população interiorana uma carga informativa que criasse o consenso necessário entre o poder central do Rio de Janeiro e a classe proprietária do Centro-Sul" 27 .

É possível, e, aliás, bastante provável que esses jornais circulassem num grupo bem mais amplo do que o formado pelo público alfabetizado, sendo lido em voz alta para os demais nos pontos de reuniões públicas, nas vendas e nas praças, uma vez que os grupos políticos que os editavam perseguiam o interesse manifesto da divulgação de 
suas idéias e o público alfabetizado não era definitivamente muito expressivo. Um indício dessa prática é a seguinte notícia veiculada no periódico "O Universal”, de Ouro Preto:

Se o correio chegar a tempo, haverá leitura dos Periódicos da Sociedade promotora d'Instrução Pública em uma das Salas do Palácio do Governo (...) e são convidados todos os Cidadãos que ali quiserem concorrer para a leitura. ${ }^{28}$

Pois bem, ocorre que exatamente nesse momento se travava uma disputa na imprensa local, repercutindo as lutas na Corte, a respeito da nomeação e conceituação dos 'pardos' entre liberais moderados e conservadores. Wlamir Silva analisou a construção de uma identidade dos pardos no discurso liberal-moderado da elite regional $^{29}$. No início dos anos trinta, terá curso uma luta ideológica, opondo liberais e caramurus, expressa através dos jornais, pela conquista desse contingente de pardos e sua incorporação à esfera de influência das correntes que buscavam se tornar hegemônicas na província. Os liberais-moderados se destacariam na construção de um discurso inclusivo dos pardos, "advogando a identidade dos interesses dos pardos com o projeto liberal" 30 . Os elementos centrais do discurso liberal que buscava a incorporação dos pardos firmavam a igualdade entre pardos, mestiços e brancos, independentemente da "diversidade de cores", e afiançavam a repulsa dos pardos ao cativeiro, diferenciando-os dos "negros" e escravos.

A condição de liminaridade vivida pelos pardos fazia que suas estratégias de inserção social passassem pelo progressivo distanciamento das marcas de origem, a cor e a condição de libertos, pela diferenciação radical dos "pretos" e "negros", termos cujos significados eram "sinônimos de escravos ou ex-escravos, portanto, referentes ao seu caráter de não cidadão" 31 . Não por acaso, os boatos que surgiam naquele período sobre uma possível reescravização dos pardos ganhavam impacto e geravam apreensão entre eles ${ }^{32}$.

O enorme contingente de "homens de cor" na região em que o crime se deu, tal como já nos referimos anteriormente, pressionava as situações de tensão e acirrava os conflitos pela igualdade nas zonas de interação social entre os pardos e crioulos, nascidos livres e forros, e os que resistiam na manutenção dos privilégios reservados aos tidos como brancos. Tais tensões imprimiam sentidos crescentemente mais delineados às identidades e suas fronteiras. Os conflitos, marcados pela disputa de um espaço social vital, davam-se em diferentes grupos sociais, nas diferentes zonas de fronteira definidas 
pela cor. Disputas pelo acesso a cargos públicos e patentes na Guarda Nacional, que opunham pardos e brancos pertencentes às classes que detinham mais recursos materiais e simbólicos; disputas por pedaços de terra e lugares de trabalho, entre os mais pobres ${ }^{33}$; disputas, enfim, na arena política, contrapondo conservadores e liberais, moderados ou exaltados, que mobilizavam os significados da "cor" e de seus "portadores". A cor tornava-se transversal na sociedade e elemento necessário a ser trabalhado como identidade.

Afirma com precisão Ivana Stolze que, se as identidades são "ilusão e contingência", "enfatizar esses aspectos contingentes e um tanto ilusórios só faz sentido se, ao invés do que se poderia supor, os relacionamos às situações de força em que se estabelecem, às suas implicações sociais, aos projetos políticos que carregam"34.

Com efeito, se a identidade pressupõe a noção de pertencimento, o jogo de autoatribuição e atribuição aos outros de valores e categorias, ela é uma ideologia da relação, definindo contraposições prontas para serem acionadas no conflito ${ }^{35}$. Como afirma Manoela Carneiro: "se a identidade repousa numa taxonomia social, resulta de uma classificação, deriva daí que ela é um lugar de enfrentamentos" ${ }^{36}$. Não que seja definida conscientemente de modo finalista, mas que assume na sua conformação, na escolha dos traços distintivos e organizadores, uma dimensão claramente política, que define sua contrastividade.

A construção das identidades se desenvolve em dois níveis que, embora imbricados na realidade, podem ser desmembrados em planos distintos de análise. Expressam, simultaneamente, estratégias organizativas, que definem o jogo de alianças e oposições como respostas às circunstâncias externas, e a afirmação de uma lógica classificatória, capaz de servir como "mapas cognitivos", permitindo aos atores sociais apreenderem as realidades vivenciadas dentro de um sistema dotado de sentido. Isso significa que os processos de identificação coletiva, de constituição de identidades sociais, devem ser apreendidos em seu aspecto relacional, na medida em que expressam, ao mesmo tempo, o modo de se representar, tanto quanto um modo de representar a realidade, fornecendo respostas tanto a "o que somos?" quanto a "onde somos?". São, portanto, escolhas estratégicas através das quais os indivíduos estabelecem relações com a realidade circundante e atuam sobre ela, ordenando-a de modo particular.

Ao constituir uma determinada forma de identificação, o grupo não o faz aleatoriamente, mas busca responder positivamente às necessidades de articular os 
interesses coletivos e de se afirmar favoravelmente ante determinada realidade, bem como estabelecer uma rede solidária de valores e referências comuns.

Deriva daí a não substancialidade das identidades, seu caráter relacional. Erigir uma identidade coletiva não significa nomear um conjunto de atributos que são próprios, imanentes ao grupo, e que corresponderiam a alguma substância que lhe fosse inerente, mas eleger um corpo de sinais, em meio às inúmeras possibilidades abertas, capazes de realizar a demarcação, capazes de definir, operando por contrastes, a lógica da distinção e o sentido de pertencimento ${ }^{37}$. A escolha dos sinais distintivos depende, portanto, do "outro" ante o qual a diferenciação se faz necessária e com o qual se estabelece uma relação significativa. É nesse sentido que Manuela Carneiro afirma que se trata de "buscar o que é operativo para servir ao contraste" ${ }^{38}$.

Voltemos ao processo. O que nos interessa, portanto, é o fato de ter-se formado no decorrer do julgamento uma aliança solidária em torno da cor. É como 'pardo' que Manoel figura no processo e é designado pelas testemunhas, e é como "negro" que Manoel sofre os ataques que redundaram na reação que terminou por matar Antônio Dias. O centro do discurso construído pelas testemunhas de defesa, ainda que não o sejam explicitamente, é que um cabra, Patrício Gonçalves, atiçara um homem branco à luta com uma lógica racista. É interessante ressaltar que o qualificativo "negro", sinônimo de escravo, é raro na documentação oficial, coisa também já assinalada por Hebe Mattos, na documentação de outras regiões ${ }^{39}$. A julgar pela leitura de processos da época, a designação parece representar a forma mais ofensiva de tratamento daqueles que traziam a descendência africana, fossem livres ou escravos. Há processos nos quais os próprios escravos rejeitam ser classificados como "negro" e reagem violentamente.

A história repetida com variações de cores e contrastes nos deixa a nítida sensação de intencionalidade: poderia ter sido preparada pelos advogados ou seria espontânea, como expressão real dos sentimentos das testemunhas ante a conduta que todos "sabem e ouviram dizer" de Patrício? Um dos depoimentos deixa claro que testemunhas tinham plena consciência do poder de suas declarações e as poderiam usar para prejudicar ou favorecer os envolvidos. A certa altura do documento lemos que, "havendo se indisposto contra o réu, a dita Rita (...) se combinou com Antônio Joaquim para culparem o mesmo réu". Ainda que implicando ou não o réu, o que importa é que o julgamento de Lauriano se transforma no julgamento de Patrício Gonçalves, que atiçou seu cunhado para a vingança contra um "negro". 
Estariam eles intencionalmente manipulando códigos culturais que, naquele momento, assumiam significados precisos em relação aos direitos e à cor? Mais acima vimos como a localização social dos "pardos" representava uma posição de liminaridade entre o estigma da ascendência africana e, portanto, escrava, e o reconhecimento social da condição de livres, resultante da inserção positivada no mundo dos 'brancos'. Daí todo o simbolismo que a denominação de "negro" carrega para esse grupo que se inscrevia nos espaços intersticiais de uma ordem baseada na hierarquia da cor que se referia a uma hierarquia da condição. Ressalte-se que a ocupação "viver de sua agência", apresentada pela ampla maioria dos brancos, pardos e crioulos, opera a diferenciação entre livres e escravos. Como afirma Hebe Mattos, "enquanto os escravos estavam associados a algum tipo de 'serviço', os homens livres 'viviam de' alguma coisa". Isso os opunha "aos cativos, que, antes de tudo, 'servem a alguém" 40 .

Talvez não seja exagerado supor que a solidariedade construída no processo com base na identidade entre "pardos" tenha tido uma clara intencionalidade e motivação, tendo sido ou não projetada a partir da estratégia da defesa.

Mas ainda um outro detalhe do processo revela certo domínio das estratégias possíveis no interior da justiça. Lauriano encontrava-se preso e Manuel Machado fora encaminhado à Junta de Justiça na capital, Ouro Preto. Uma vez lá, Manuel exime-se do crime antes confessado e, com a ajuda de testemunhas, transfere a culpa pela morte de Antônio Dias a Lauriano, que lhe teria dado o golpe fatal com uma foice. Inocentado pela Junta de Justiça, Manuel retorna e passa a assumir publicamente que fora ele o verdadeiro autor do golpe fatal, o que define o julgamento de Lauriano. No arrazoado de defesa apresentado pelo advogado de Lauriano ao júri, em São João Del Rei, a estratégia é recontada:

Todos sabem que foi ele quem feriu e matou a Antônio Dias de Carvalho; todos admiram o seu valor, ânimo e intrépida resolução, mas como se procedia a devassa e se queria salvá-lo mudou-se a face das coisas: espíritos tíbios e fracos, perversos ou destros, ignorantes ou sábios o aconselharam que não fizesse tal confissão. (...) Este mesmo Manuel Machado apenas se viu livre por sentença da Junta de Justiça, tomou aquela linguagem de pureza e de justiça da qual usava antigamente, dando à inocência do réu [Lauriano] a homenagem que lhe era devida $^{41}$. 
As testemunhas são novamente peças-chave no desfecho do processo, revelando um perfil de Lauriano como homem "de prudência e verdade em todos os seus tratos, sendo incapaz de faltar o respeito à lei e todas as autoridades", e que teria se visto envolvido na briga desarmado, já que se dirigira ao local "com sua mulher e três filhas por ser ele o que ia tirar a novena em razão de [ser] sacristão da Ermida”. Além disso, afirmam ter sido mesmo Manuel que matara a vítima com sua espada, ou porque ele mesmo lhes dissera ou porque viram a espada ensangüentada.

Assim, o júri responde os quesitos acusatórios "pela parte negativa" e o juiz sentencia, em cinco de junho de 1834, que, “à vista da decisão do júri, com a qual me conformo, absolvo o réu da acusação intentada, o seu nome seja riscado do rol dos culpados, e se dê baixa na culpa" ${ }^{, 42}$.

Toda a versão construída para inocentar Lauriano é contraditória com o auto de corpo de delito que, tal como citado acima, atribuiu a morte a dois ferimentos feitos com instrumentos diferentes: uma espada e uma foice ou machado, indicando a participação de ambos no crime. Além disso, Manuel Machado e Lauriano eram compadres. Três anos antes Lauriano se tornara padrinho de uma filha de Manuel $^{43}$. Creio ser desnecessário enfatizar o significado do compadrio e os vínculos sociais e compromissos de lealdade que a relação estabelecia.

A exemplaridade desta história se presta a resumir aspectos que surgem, embora não com essa riqueza ou de forma tão condensada, em vários processos examinados. A intervenção dos diversos atores no andamento e curso do processo e os usos dos recursos disponíveis pela legislação denunciam a capacidade de atuar dentro do campo jurídico, em atenção às suas regras e procedimentos. Isso certamente indica a presença de uma atividade advocatícia expressiva e acessível a homens como Lauriano e Manuel Machado ${ }^{44}$. Alguns processos materializam batalhas judiciais envolvendo promotores, advogados e juízes, cujas reviravoltas, por sua vez, demonstram a dificuldade de antecipar os resultados das disputas travadas no interior da justiça.

Apenas podemos especular sobre as possíveis repercussões dos debates da época na condução do processo dos compadres Manuel e Lauriano, pardos que teriam assassinado um branco instigado a desforrar-se de um "negro" por seu cunhado. De qualquer modo, não deixa de ser sugestivo o fato de que a argumentação que conduz o processo consiste em transformar Patrício, o cunhado, em responsável por instigar um branco a vingar-se de um "negro". 
Estariam os solicitadores do réu empenhados em construir uma versão que fosse mobilizadora, por sua significação política dos juízes e jurados? O juiz municipal, Francisco Antônio da Costa, tornou-se, logo depois, presidente da Sociedade Defensora da Liberdade; o Juiz de Direito, Gabriel Mendes dos Santos, como vereador, participou da resistência à sedição de Ouro Preto em 1833; o promotor Domiciano Leite Ribeiro, mais tarde Visconde de Araxá, iniciou sua vitoriosa carreira política nas hostes liberais. Eram, portanto, todos liberais compromissados com a perspectiva de inserção e distinção dos pardos. Além disso, o padre Francisco de Paula Machado, que presidiu ao corpo de jurados, era padrinho de uma filha de Manoel Machado.

$\mathrm{Ou}$ teriam sido as próprias testemunhas, cientes das transformações que ganhavam curso, a ler no episódio o não-reconhecimento por parte de um branco da condição de um pardo e de sua inserção diferenciada na sociedade?

Antônio Dias morreu por tentar reduzir um pardo ao lugar social reservado aos "negros". Os compadres Manuel e Lauriano, pardos, foram absolvidos por legítima defesa da vida. Poderíamos acrescentar: a legítima defesa de seus lugares na hierarquia do mundo.

\section{Referência Bibliográfica}

BARTH, Fredrik. Introducion. In: Los Grupos Étnicos e sus Fronteras. México: Fondo de Cultura Económica, 1976.

BERGAD, Laird, W. Slavery and the demographic and Economic History of Minas Gerais, Brazil, 1720 -1888. Cambridge: University Press, 1999.

CAMPOS, Maria Augusta de Amaral. A marcha da civilização: as vilas oitocentistas de São João del-Rei e São José do Rio das Mortes. Belo Horizonte: FAFICH/UFMG, 1998 (dissertação de mestrado).

CARVALHO, José Murilo de. Cidadania: tipos e percursos. Estudos Históricos, Rio de Janeiro, n. 18, 1996.

CUNHA MATOS, Raimundo José da. Corografia histórica da província de Minas Gerais (1837). B. Horizonte: Itatiaia/São Paulo: Edusp, 1981.

CUNHA, Manoela Carneiro da. "Etnicidade: Da Cultura Residual mas Irredutível", In: Revista de Cultura e Política, v. 1: 35-39, 1979.

CUNHA, Manoela Carneiro da. Negros Estrangeiros. Os Escravos Libertos e sua Volta à África. São Paulo: Ed. Brasiliense, 1985.

GINZBURG, Carlo. Mitos, emblemas, sinais: morfologia e história. São Paulo: Schwarcz, 1989.

LENHARO, Alcir. As tropas da moderação: o abastecimento da Corte na formação política do Brasil, 1808-1842. São Paulo: Símbolo, 1979. 
LIBBY, D. C.; PAIVA, C. A. Alforrias e forros em uma freguesia mineira: São José Del Rey em 1795. Revista Brasileira de Estudos da População, Campinas, v. 17, n. 1/2, pp. 17-46.

LIMA, Ivana Stolze. Cores, marcas e falas: sentidos da mestiçagem Império do Brasil. Rio de Janeiro: Arquivo Nacional, 2003.

LUCCOCK, John. Notas sobre o Rio de Janeiro e partes meridionais do Brasil. Belo Horizonte: Itatiaia/ São Paulo: Edusp, 1975.

MATTOS, Hebe Maria._As cores do silêncio: significados da liberdade no sudeste escravista - Brasil século XIX. Rio de Janeiro: Arquivo Nacional, 1995.

Os últimos cativos: direitos privados e direitos civis no Brasil oitocentista.

Revista de História, X Encontro Regional de História da ANPUH MG. Belo Horizonte, n. 6, pp. 27-40, 1996.

MAXWEL, Kenneth. A Devassa da Devassa - A Inconfidência Mineira: Brasil e Portugal 1750-1808. Rio de Janeiro: Paz e Terra, 1978.

OLIVEIRA, Roberto Cardoso. Identidade, Etnia e Estrutura Social. São Paulo: Livraria Pioneira Editora, 1976.

RIBEIRO, Gladys Sabina. A liberdade em construção: identidade nacional e conflitos antilusitanos no primeiro reinado. Rio de Janeiro: Relume-Dumará/Faperj, 2002.

. . Metáforas e ações na longa luta pela liberdade: conflitos entre "portugueses" e "homens de cor", Corte do Rio de Janeiro, 1827-1834. Revista Tempo, Rio de Janeiro, n. 10, pp. 97-117.

SILVA, Ana Rosa Cloclet da. Identidades em construção. O processo de politização das identidades coletivas em Minas Gerais, de 1792 a 1831. Almanaque Brasiliense, n. 1, maio de 2005, Revista Eletrônica IEB/USP, http://www.almanack.usp.br.

SILVA, Wlamir. Homens de cor! Irmãos!: os pardos na pedagogia liberal-moderada mineira do período regencial. Estudos Ibero-Americanos, PUCRS, v. XXXI, n. 1, pp. 61-77, junho, 2005.

SILVA, Wlamir. Liberais e povo: a construção da hegemonia liberal-moderada na Província de Minas Gerais (1830-1834). Rio de Janeiro, IFCS/UFRJ, 2002 tese de doutorado).

VAN VELSEN, J. A análise situacional e o método de estudo de caso detalhado. In: FELDMAM-BIANCO, Bela (org.). Antropologia das sociedades contemporâneas. São Paulo: Global, 1987, pp. 355-369.

VELLASCO, Ivan de Andrade. As seduções da ordem: violência, criminalidade $e$ administração da justiça. Minas Gerais - século 19. Bauru: Edusc/ANPOCS, 2004.

ZENHA, Celeste. As Práticas da Justiça no Cotidiano da Pobreza: um estudo sobre o amor, o trabalho e a riqueza através dos processos penais. Niterói: UFF, 1984 (dissertação de mestrado).

VELLASCO, Ivan de Andrade. The Colour Solidarity Networks: the case of the 'compadres' Manoel and Laurino. História, São Paulo, v. 25, n. 1, p. 147-169, 2006.

Abstract: This article is based on the analysis of a criminal lawsuit from 1831, in which the accused ones, who were "mulattos", were charged with a white man murder. In the testimonies of the lawsuit, it is possible to identify a supportive alliance among the "mulattos", in relation to the categories that define the positions and judgements concerning to the crime. Witnesses, both "mulattos" and "negros", free and manumitted slaves, have produced a consensus, hence building a version against the victim, the white man. A view on right and wrong 
promotes solidarity in everybody and, within this view, a specific perception about what unites "mulattos", "negros", manumitted slaves and "cabras". We propose that the solidarity based on the identity among the "mulattos" can be understood in relation to the motivations associated to their emersion in the political debates of the time, concerning to their conceptualization and inclusion in the nation project. This article represents an attempt to understand, in the available indexes, the constitution of identity processes based on color and condition, fundamental categories in the slave society.

Keywords: "mulattos", solidarity network, identity.

Artigo recebido em 10/2006. Aprovado em 11/2006.

\section{NOTAS}

* Professor Adjunto do Departamento de Ciências Sociais da Universidade Federal de São João del-Rei UFSJ, Minas Gerais, Brasil. Pesquisador do PRONEX "Nação e Cidadania: novos horizontes", FAPERJ/CNPq.

${ }^{1}$ GINZBURG, Carlo. Mitos, emblemas, sinais: morfologia e história. São Paulo: Ed. Schwarcz, 1989.

2 VAN VELSEN, J. A análise situacional e o método de estudo de caso detalhado. In: FELDMAMBIANCO, Bela (org.). Antropologia das sociedades contemporâneas. São Paulo: Global, 1987, pp. 345374, p. 355.

${ }^{3}$ VAN VELSEN, op. cit., p. 369. Nesse sentido, creio que a abordagem que o autor define como "análise situacional" é de grande valia para a interpretação desses fragmentos de conflitos que os processos judiciais espelham. Ao enfatizar o "estudo das normas em conflito" na pesquisa antropológica, o autor nos fornece perspectivas de análise que creio de todo pertinentes para o estudo especificamente dessas fontes, sobretudo se quisermos ultrapassar as leituras que dicotomizam "resistência" e "controle", "submissão" e "revolta".

${ }^{4}$ Uma versão parcial desse texto foi apresentada como comunicação no XV Encontro Regional da ANPUH-MG. Utilizei-me desse processo em trabalho anterior, indicando já algumas questões que vão neste texto. Boa parte da descrição e discussão do documento segue o que havia exposto naquele trabalho. Ver Vellasco, Ivan de Andrade. As seduções da ordem: violência, criminalidade e administração da justiça. Minas Gerais - século 19. Bauru: Edusc/ANPOCS, 2004.

${ }^{5}$ Ver Código do Processo Criminal do Império do Brasil.

${ }^{6}$ CARVALHO, José Murilo de. Cidadania: tipos e percursos. Estudos Históricos, Rio de Janeiro, n. 18, 1996.

7 “A penetração na esfera do poder do setor abastecedor, até então excluído, confirmou-se em 1831. O comércio de abastecimento e a fixação de interesses na Corte é que viabilizaram a projeção dos seus representantes políticos. Ganhando o mercado, os políticos do abastecimento começaram também a ganhar notoriedade a partir da experiência parlamentar de 1826". LENHARO, Alcir. As tropas da moderação: o abastecimento da Corte na formação política do Brasil, 1808-1842. São Paulo: Símbolo, 1979 , p. 88.

${ }^{8}$ CUNHA MATOS, Raimundo José da. Corografia histórica da província de Minas Gerais (1837). B. Horizonte: Itatiaia/São Paulo: Edusp, 1981, v. 1, p. 126.

${ }^{9}$ Os autores afirmam que, em Minas Gerais, "no final do século, o segmento de cor da população - os forros e os nascidos livres - superou em muito a população branca, e durante o século XIX também iria superar a população escrava”. LIBBY, D. C.; PAIVA, C. A. Alforrias e forros em uma freguesia mineira: São José Del Rey em 1795. Revista Brasileira de Estudos da População, Campinas, v. 17, n. 1/2, pp. 1746, p. 2 .

${ }^{10}$ LIBBY, D. C.; PAIVA, C. A., op. cit. Nesse artigo Paiva \& Libby analisam os dados de um documento denominado "Rol dos Confessados desta Freguezia de S. Antonio da Villa de S. Joze, Comarca do Rio das Mortes, deste prezente anno de 1795”, pertencente ao acervo do Instituto Histórico e Geográfico de Tiradentes. É interessante notar que, como indicam os autores, no Rol, "indivíduos que haviam sido alforriados foram escrupulosamente listados como forros; os demais crioulos, pardos, cabras e mestiços, 
como nascidos livres”. Isso indica que a denominação pardo já era então predominantemente designadora de indivíduos não-brancos nascidos livres.

${ }^{11}$ Pardo era então a designação comum a homens livres de cor. Mais do que referência à cor, significava a condição de livre, já que negros e crioulos eram formas de designação da população escrava. Hebe Mattos chama a atenção para os significados do qualificativo “pardo" nesse período: “a designação de 'pardo' era usada, antes, como forma de registrar uma diferenciação social, variável conforme o caso, na condição mais geral de não-branco. Assim, todo escravo descendente de homem livre (branco) tornava-se pardo, bem como todo homem nascido livre que trouxesse a marca de sua ascendência africana - fosse mestiço ou não (...) Desta forma, o qualificativo 'pardo' sintetizava, como nenhum outro, a conjunção entre classificação racial e social no mundo escravista. Para tornarem-se simplesmente 'pardos', os homens livres descendentes de africanos dependiam de um reconhecimento social de sua condição de livres, construído com base nas relações pessoais e comunitárias que estabeleciam”. MATTOS, Hebe Maria. As cores do silêncio: significados da liberdade no sudeste escravista - Brasil século XIX. Rio de Janeiro: Arquivo Nacional, 1995, pp. 34, 35.

${ }^{12}$ CUNHA MATOS, Raimundo José da. Corografia histórica da província de Minas Gerais... v. 2, p. 56.

${ }^{13}$ SILVA, Ana Rosa Cloclet da. Identidades em construção. O processo de politização das identidades coletivas em Minas Gerais, de 1792 A 1831. Almanaque Brasiliense, n. 1, maio de 2005, Revista Eletrônica IEB/USP, http://www.almanack.usp.br.

${ }^{14}$ Arquivo do Museu Regional de São João del-Rei (AMRSJDR), cx. Processo Crime 06-01, 1831, folha 26.

${ }^{15}$ AMRSJDR, idem, folha 21.

${ }^{16}$ Para uma abordagem dos processos como "fábulas", ver ZENHA, Celeste. As Práticas da Justiça no Cotidiano da Pobreza: um estudo sobre o amor, o trabalho e a riqueza através dos processos penais. Niterói: UFF, 1984 (dissertação de mestrado).

${ }^{17}$ Ver OLIVEIRA, Roberto Cardoso. Identidade, Etnia e Estrutura Social. São Paulo: Livraria Pioneira Editora, 1976.

${ }^{18}$ Rol dos culpados, AMRSJDR. O rol dos culpados eram os livros nos quais eram lançados os nomes dos denunciados nas querelas ou acusados nas devassas.

${ }^{19}$ RIBEIRO, Gladys Sabina. Metáforas e ações na longa luta pela liberdade: conflitos entre "portugueses" e "homens de cor", Corte do Rio de Janeiro, 1827-1834. Revista Tempo, Rio de Janeiro, n. 10, pp. 97-117, p. 98.

${ }^{20}$ Ver da autora RIBEIRO, Gladys Sabina. A liberdade em construção: identidade nacional e conflitos antilusitanos no primeiro reinado. Rio de Janeiro: Relume-Dumará/Faperj, 2002.

${ }^{21}$ LIMA, Ivana Stolze. Cores, marcas e falas: sentidos da mestiçagem Império do Brasil. Rio de Janeiro: Arquivo Nacional, 2003.

22 Dados MAXWEL, Kenneth. A Devassa da Devassa - A Inconfidência Mineira: Brasil e Portugal 1750-1808. Rio de Janeiro, Paz e Terra, 1978 e BERGAD, Laird W. Slavery and the demographic and Economic History of Minas Gerais, Brazil, 1720 -1888. Cambridge: University Press, 1999.

${ }^{23}$ SAINT-HILAIRE, Auguste de. Viagem pelo distrito dos diamantes e litoral do Brasil. B. Horizonte: Itatiaia/ São Paulo: Edusp, 1974, p. 106.

${ }^{24}$ SAINT-HILAIRE, op. cit., p. 113.

${ }^{25}$ E ainda posteriormente, "O Americano" (1840), “O Despertador Mineiro" (1842), e “A Ordem" (18421844). As informações sobre as datas de circulação foram extraídas de CAMPOS, Maria Augusta de Amaral. A marcha da civilização: as vilas oitocentistas de São João del-Rei e São José do Rio das Mortes. Belo Horizonte: FAFICH/UFMG, 1998 (dissertação de mestrado).

${ }^{26}$ No Jornal $O$ Mentor das Brasileiras, de 8 de abril de 1831, noticiava-se a criação em S. João de "huma nova Sociedade secreta" para "fazer frente ao Partido dos federalistas" - a Sociedade da União e Lealdade e publicava carta de uma mulher "cabra" conclamando os brasileiros contra os portugueses, em referência à noite das garrafadas; novamente, em 15 de abril de 1831, dava notícias sobre a luta antilusitana nos últimos dias do Império.

${ }^{27}$ LENHARO, Alcir. As tropas da moderação... Op. cit., p. 124.

28 Citado em SILVA, Wlamir. "Liberais e povo": a construção da hegemonia liberal-moderada na Província de Minas Gerais (1830-1834). Rio de Janeiro: IFCS/UFRJ, 2002 (tese de doutorado), p. 146.

${ }^{29}$ SILVA, Wlamir. Homens de cor! Irmãos!: os pardos na pedagogia liberal-moderada mineira do período regencial. Estudos Ibero-Americanos, PUCRS, v. XXXI, n. 1, p. 61-77, junho, 2005.

${ }^{30}$ SILVA, Wlamir. Homens de cor... Op. cit., p. 70.

${ }^{31}$ MATTOS, Hebe Maria. Os últimos cativos: direitos privados e direitos civis no Brasil oitocentista. Revista de História, X Encontro Regional de História da ANPUH MG. Belo Horizonte, n. 6, pp. 27-40, 1996. 
${ }^{32}$ SILVA, Wlamir. Homens de cor... Op. cit.

33 Como afirma Gladys Sabina Ribeiro, "as lutas pela sobrevivência eram sobretudo "políticas"”. RIBEIRO, Gladys Sabina. Metáforas e ações na longa luta pela liberdade... Op. cit., p. 105.

${ }^{34}$ LIMA, Ivana Stolze, op. cit., p. 18.

${ }^{35}$ OLIVEIRA, Roberto Cardoso de, op. cit.

${ }^{36}$ CUNHA, Manoela Carneiro da. Negros Estrangeiros. Os Escravos Libertos e sua Volta à África. São Paulo: Brasiliense, 1985, p. 206.

37 "Os traços que são tomados em conta não são a soma de diferenças 'objetivas', e sim somente aquelas que os atores mesmos consideram significativas". BARTH, Fredrik. Introducion. In: Los Grupos Étnicos y sus Fronteras. México: Fondo de Cultura Económica, 1976, p. 15.

${ }^{38}$ CUNHA, Manoela Carneiro da. Etnicidade: Da Cultura Residual mas Irredutível. In: Revista de Cultura e Política, v. 1: 35-39, 1979, p. 36.

${ }^{39}$ MATTOS, Hebe Maria. As cores do silêncio... Op. cit.

${ }^{40}$ MATTOS, Hebe Maria. As cores do silêncio... Op. cit., p. 37. No Vocabulário Portuguez e Latino do Padre Raphael Bluteau, "agência" é sinônimo de ofício, indústria.

${ }^{41}$ AMRSJDR, idem, folha 75.

${ }^{42}$ AMRSJDR, idem, folha 92.

${ }^{43}$ Registro de Batismos da Matriz de Nossa Senhora do Pilar, livro 35, página 199.1, 20/06/1827. A documentação paroquial referente aos registros de batismos e casamentos encontra-se totalmente indexada num banco de dados disponível para pesquisas, construído pela Prof ${ }^{a}$. Silvia Brügger. Agradeço ao Bolsista do PIBIC Gabriel Nicolau a pesquisa dos vínculos entre os personagens do processo.

${ }^{44}$ Em sua estada em São João del-Rei, John Luccock observa que "tanto os padres como os advogados parecem existir em grande número aqui, tal como se dá para outras localidades sujeitas à Coroa portuguesa, muito além mesmo do que o poderiam exigir os legítimos reclamos da Justiça e da Religião". LUCCOCK, John. Notas sobre o Rio de Janeiro e partes meridionais do Brasil. Belo Horizonte: Itatiaia/ São Paulo: Edusp, 1975, p. 305. 